\title{
Effects of Watermelon Seed Extract (Citrullus Vulgaris) on Spermatogenesis in Rat
}

\author{
Arash Khaki $^{1 *}$, Fatemeh Fathiazad ${ }^{2}$, Mohammad Nouri ${ }^{1}$
}

\section{Article History:}

Received July 2013

Accepted September 2013

Available online September 2013

\section{Keywords:}

Citrullus vulgaris,

Rat

Sperm

\section{Corresponding Author:}

Arash Khaki, Women's

Reproductive Health Research

Center, Tabriz University of

Medical Sciences, Tabriz, Iran.

Tel: +989143138399

Email: arashkhaki@yahoo.com

\begin{abstract}
:
Objective: Citrullus vulgaris is an antioxidant that has been shown to reduce oxidative stress. Worldwide studies have been done in order to use as herbal medicine in different fields of medicine. Based on ancient Persians traditional books use of herbal medicine has positive effect on treatment of different diseases. Previous studies confirmed antioxidants have significant effect on infertility by their role on reactive oxygen species. The aim of this study was to see effect of this herb on spermatogenesis.

Material and Methods: Wistar male rats $(\mathrm{n}=20)$ were allocated into two groups, control group $(\mathrm{n}=10)$ and citrullus vulgaris (C.V) group $(\mathrm{n}=10)$ that received 55mg.kg-1.day-1 C.V by gavage method for 4 weeks; however, the control group just received an equal volume of distilled water daily. Animals were kept in standard condition. In 28th day, testicle tissues were collected then prepared for sperm analysis.

Results: sperm parameters significantly increased in experimental group in comparison to control group $(\mathrm{P}<0.05)$. Conclusion: Since in our study 55mg.kg-1 (C.V) has significantly increased sperm population, motility and viability, it seems that using it in infertile patients has beneficial effects.
\end{abstract}

1- Women's Reproductive Health Research Center, Tabriz University of Medical Sciences, Tabriz, Iran. 2- Department of Pharmacognosy, Tabriz University of medical sciences, Tabriz, Iran 


\section{Introduction:}

Phytotherapy has recently gained popularity in Europe and the United States. The watermelon fruit has deep green or yellow colored smooth thick exterior rind with gray or light green vertical stripes. Inside the fruit is pink, red or even yellow in color with small black seeds embedded in the middle third of the flesh. Generally, watermelon flesh is the main consumable portion; however, outer rind is also used in some parts of the world $(1,2)$. Watermelon with red flesh is a significant source of lycopene. Preliminary researches indicate that the consumption of watermelon may have antihypertensive effects (3). water. Watermelon like many other fruits is a source of vitamin C. The amino-acid citrulline was first extracted from watermelon and analyzed. Watermelon contains a significant amount of citrulline and after consumption of several kilograms, an elevated concentration is measured in the blood plasma; this could be mistaken for citrullinaemia or other urea cycle disorders $(4,5)$. In human nutrition, watermelon contributes to the integrity of the blood vessels. Various preliminary studies reveal novel pharmaceutical properties of it. Flavonoids are products of plant metabolism and have different phenolic structures $(6,7)$. Enhanced oxidative stress and changes in antioxidant capacity are considered to play an important role in the pathogenesis of chronic diabetes mellitus $(8,9)$. Although the mechanisms underlying the alterations associated with diabetes mellitus are presently not well understood, hyperglycemia leads patients to increased oxidative stress because the production of several reducing sugars (through glycolysis and the polyol pathway) is enhanced. These reducing sugars can easily react with lipids and proteins (nonenzymatic glycation reaction) and increase the production of reactive oxygen species (ROS) $(10,11,12)$. The balance of ROS and antioxidant is a major mechanism in preventing damage by oxidative stress. Therefore, the dietary supplement of antioxidants such as vitamins, flavonoids has been used to prevent the occurrence of many chronic diseases (13, 14). Therefore, we decided to study the effect of Citrullus vulgaris seeds as an antioxidant on sperm parameters.

\section{Material \& Methods:}

\section{Animals}

Twenty adult wistar albino male rats which were 8 weeks old and weighing $250 \pm 10 \mathrm{~g}$, were obtained from animal facility of pasture institute of Iran. Male rats were housed in temperature controlled rooms (25 C) with constant humidity (4070\%) and $12 \mathrm{~h} / 12 \mathrm{~h}$ light/ dark cycle before using in experimental protocols. All animals were treated in accordance with the Principles of Laboratory Animal Care. The experimental protocol was approved by the Animal Ethical Committee in accordance with the guide for the care and use of laboratory animals prepared by Tabriz medical University. All Rats were fed a standard diet and water. The daily intake of animal water was monitored at least one week before starting treatment in order to determine the amount of water needed for each experimental animal. Thereafter, the wistar male rats $(n=20)$ were randomly allocated into two groups, control group $(n=10)$ and experimental group $(\mathrm{n}=10)$ that received 55mg.kg-1.day1 Citrullus vulgaris by gavage method for 4 weeks; however, the control group just received an equal volume of distilled water daily.

\section{Preparation of extract:}

Citrullus vulgaris seeds were bought from local market in Tabriz City of Iran. Seeds were washed and dried in room temperature. This hydro alcoholic extract was kept in refrigerator for all experiments. 2.3. Surgical procedure

In 28th day, the Pentobarbital sodium (40 $\mathrm{mg} / \mathrm{kg}$ ) was administered intra peritoneal for anesthesia, and the peritoneal cavity was opened through a lower transverse abdominal incision. Thereafter, epididymis in control and experimental groups were immediately removed. The weights of epididymis in both groups were registered. The animals were decapitated between 9:00 AM and 11:00 AM.

2.4. Epididymis weight, Sperm count, viability and motility

Sperms from the cauda epididymis were released by cutting into $2 \mathrm{ml}$ of medium (Hams F10) containing 0.5\% bovine serum 
albumin (15).After $5 \mathrm{~min}$ incubation at $37^{\circ} \mathrm{C}$ (with 5\% CO2), the cauda epididymis sperm reserves were determined using the standard hemocytometric method and sperm motility was analyzed with microscope (Olympus IX70) at 10 field and reported as mean of motile sperm according to WHO method (16).

\section{Statistical analysis}

Statistical analysis was done using the independent sample T-test for comparison of data in the control group with the experimental groups. The results were expressed as Mean \pm S.E.M (standard error of means). P-value less than 0.05 were considered significant and are written in the parentheses.

\section{Results :}

Weight of Epididymis:

The obtained results in this study were illustrated in table 1 . There was no significant difference in epididymis weights between two groups.

Sperm motility, viability and count :

Administration of $55 \mathrm{mg} / \mathrm{kg}$ Citrullus vulgaris extract for 28 consecutive days significantly increased Sperm concentrations, motility and viability in experimental group as compared with the control group $(\mathrm{P}<0.05)$ (Table 1$)$.

\section{Discussion:}

In this study, male rats were subdivided into two groups, control and experimental group. Experimental group receiving watermelon seed extract (citrullus vulgaris) showed increased sperm motility, viability and concentration in comparison to control group. This increase could be due to the protective effect of citrullus vulgaris seed extract administration. Phytonutrients with significant role in human health and disease prevention decline incidences of several physiological threats (17). These phytonutrients have anti-oxidative activity due to having phenolics and carotenoid compounds (18). Watermelon has numerous antioxidants (e.g. lycopene, betacarotene) and some specific amino acids (e.g. arginine, citrulline). Fresh watermelon consumption $\neg$ is considered a healthy addition to diet owing to the presence of lycopene (19). Antioxidants can interfere with the oxidation process by reacting with free radicals, chelating catalytic metals, acting as oxygen scavengers $(20,21)$ and preventing lipid auto oxidation $(22,23)$. Worldwide studies have been done in order to use of herbal medicine in different fields of medicine. Based on ancient Persians traditional books use of herbal medicine has positive effect on treatment of different diseases especially infertility. Several studies have reported that antioxidants and vitamin $\mathrm{A}, \mathrm{B}, \mathrm{C}$, and $\mathrm{E}$ in diet can protect sperm DNA from free radicals and increase blood-testis barrier stability $(24,25)$.

Evidences suggest that certain phytochemicals found in citrus sources, such as flavonoids and limonoids, have major role in treating or retarding chronic diseases. Positive properties of these phytochemicals include anti-oxidative, anti-carcinogenic, cardiovascular protective, neuro-protective, bone health promotion and antiinflammatory protection. Antioxidants protect DNA and other important molecules from oxidation and can improve sperm quality and consequently increase fertility rate in men (26). Therefore, it is suggested that, increased use of herbal medicine, fruit, vegetables, onion, tea and black burgundy grape which are full of flavonoids and citrullus vulgaris seeds such as herbal antioxidant can improve sperm parameters and increase chances in infertile couple to get new life.

\section{Conclusion:}

This study shows increase in sperm viability, motility and population so it seems it as positive effects on male infertility.

\section{Acknowledgments:}

This research was supported by Women's Reproductive Health Research Center, Tabriz University of Medical Sciences, Tabriz, Iran. The code of this research protocol was 9018 . 
Table 1. Sperm parameters and epididymis weight of control and experimental groups.

\begin{tabular}{|l|c|c|}
\hline Variables & Control group (n=10) & Citrullus vulgaris group (n=10) \\
\hline epididymis (gr) & $1 \pm 0.33$ & $1 \pm 0.55$ \\
\hline $\begin{array}{l}\text { Sperm concentration (total count) } \\
\text { (No of sperm/rat'106) }\end{array}$ & $38.40 \pm 1.29$ & $63.20 \pm 2.35^{*}$ \\
\hline Motility (\%) & $33 \pm 3$ & $70 \pm 1.79^{*}$ \\
\hline Viability(\%) & $58 \pm 2.55$ & $89.60 \pm 1.47^{*}$ \\
\hline
\end{tabular}




\section{References:}

1. Touhami M, Laroubi A, Elhabazi K, Loubna F, Zrara I, Eljahiri, et al. Lemon juice has protective activity in a rat urolithiasis model. BMC urology. 2007; 7(1): 18.

2. Levi A, Thomas CE, Keinath AP, Wehner TC. Genetic diversity among watermelon (Citrullus lanatus and Citrullus colocynthis) accessions. Genet. Resour. Crop Evol. 2001; 48: 559-566.

3. Figueroa A, Sanchez-Gonzalez MA, Wong A, Arjmandi BH. Watermelon extract supplementation reduces ankle blood pressure and carotid augmentation index in obese adults with prehypertension or hypertension". American journal of hypertension. 2012; 25 (6): 6403.

4. Tlili I, Hdider C, Lenucci MS, Ilahy R, Jebari H, Dalessandro G. Bioactive compounds and antioxidant activities during fruit ripening of watermelon cultivars. J Food Compost Anal. 2013; 24(7), 923-928.

5. Mandel H, Levy N, Izkovitch S, Korman, S H.Elevated plasma citrulline and arginine due to consumption of Citrullus vulgaris (watermelon). Berichte der deutschen chemischen Gesellschaft. 2005; 28 (4): 467-472.

6. Guzmán-Gutiérrez SL, Navarrete A . Pharmacological exploration of the sedative mechanism of hesperidin identified as the active principle of Citrus sinensis flowers. Planta. Med. 2009; 75(4): 295-301.

7. Ohtsuki K, Abe A, Mitsuzumi H. Glucosyl hesperidin improves serum cholesterol composition and inhibits hypertrophy in vasculature. J Nutr Sci Vitaminol. 2003; 49(6): 447450 .

8. Baynes JW, Thorpe SR.Role of oxidative stress in diabetic complications: a new perspective on an old paradigm. J of Diabetes.1999; 48: 1-9.

9. Wolff SP, Jiang ZY, Hunt JV.Protein glycation and oxidative stress in diabetes mellitus and ageing. J. Free Radic Biol. Med. 1991; 10: 339 -52.

10. Mrowicka M. The role of disorders of the prooxidant-antioxidant system in diabetes etiopathology. Postepy Hig Med Dosw. 2011;65:534-541.

11. Yokozawa T, Cho EJ, Park CH, Kim JH. Protective Effect of Proanthocyanidin against Diabetic Oxidative Stress. Evid Based Complement Alternat Med. 2012:623879

12. Moussa SA. Oxidative stress in diabetes mellitus. Romanian J Biophys. 2008; 18(3): 225236.

13. García-Lafuente A, Guillamón E, Villares A, Rostagno MA, Martínez JA. Flavonoids as anti-inflammatory agents: implications in cancer and cardiovascular disease. Inflamm Res. 2009; 58(9): 537-552. 
14. Khaki A, Fathiazad F, Nouri M, Khaki AA, Jabbari-kh H, Hammadeh M. Evaluation of androgenic activity of Allium cepa on spermatogenesis in Rat. Folia Morphologica. 2009; 68(1): 45-51.

15. Feng R, He W, Ochi H. A new murine oxidative stress model associated with Senescence. Mech Ageing Dev. 2001; 122: 547-559.

16. World Health Organization (1999.). WHO Laboratory Manual for the Examination of Human Semen and Semen-Cervical Mucus Interaction. 4th ed. Cambridge University Press, New York.

17. Engelhard YN, Gazer B, Paren E. Natural antioxidants from tomato extract reduce blood pressure in patients with grade-1 hypertension: A double blind, placebo-controlled pilot study. Am Heart J. 2006; 151: 1-6.

18. Shahidi, F. Nutraceuticals and functional foods: Whole versus processed foods. Trends Food Sci. Technol. 2009; 20: 376-387.

19. Kamil MM, Gamal MF, Shaheen MS. Fourier Transformer Infrared Spectroscopy for Quality Assurance of Tomato Products. J Am Sci.2011; 7: 558-572.

20. Shahidi, F. and P.K.J.P.D. Wanasundara. Phenolic antioxidant. Crit. Rev. Food Sci Nutr. 1992; 32: 67-103.

21. Sánchez-Moreno C, Larrauri J, Saura-Calixto F. Free radical scavenging capacity and inhibition of lipid oxidation of wines, grape juices and related polyphenolic constituents. Food Research International. Food Res Int. 1999; 32(6), 407-412.

22. Bondet V, Brad-William W, Berset C. Kinetics and mechanisms of anti-oxidant activity using DPPH free radical method. LWT Food Sci. Technol. 1997; 31: 609-615.

23. Brand-Williams W, Cuvelier ME and Berset C. Use of a free radical method to evaluate antioxidant activity. LWT Food Sci. Technol. 1997; 28: 25-30.

24. Jedlinska-Krakowska M, Bomba G, Jakubowski K, Rotkiewicz T, Jana B, Penkowski A . Impact of oxidative stress and supplementation with vitamins $\mathrm{E}$ and $\mathrm{C}$ on testes morphology in rats. J Reprod Dev. 2006; 52: 203-209.

25. Fathiazad F, khak A, Nouri M, Khaki A.A. Effect of Cinnamon Zeylanicum on serum Testosterone and anti-oxidants levels in Rats. IJWHR. 2013; 1(1): 29-35.

26. Yang HS, Han DK, Kim JR, Sim JC. Effects of alpha-tocopherol on cadmium-induced toxicity in rat testis and spermatogenesis. J Korean Med Sci. 2006; 21:445-451. 